mirror will be small, but the possibility of photographing extremely faint stars, especially in the spiral nebulæ, makes such a powerful concentration of light highly advantageous. Dr. Ross, who will devote himself to these optical problems during the coming year, also believes that a lens can be designed, for use in the converging beam, which will serve when desired to give a much larger field, also with a short equivalent focal length. It is planned to use a Cassegrainian combination with a ratio of $\mathrm{F}$ : 10, having a sharp field $30^{\prime}$ (17 inches) in dia. meter, for spectrographic and other work. A Coudé arrangement similar to that of the 100-inch Hooker telescope, permitting the images of celestial objects to be formed in a constant temperature laboratory, for study with large fixed spectrographs, radiometers, or other auxiliary instruments, is also projected."

The device of overcoming the difficulties of casting so large a disc by making only the surface layer of homogeneous material recalls a somewhat similar idea put forward by Sir Norman Lockyer so long ago as the year 1884. He proposed the construction of an 8-foot reflector, of which the body of the mirror was to be of porcelain and the surface of glass. At that time astronomical photography was in its infancy, and Lockyer's ideas of the work which could be done with such an instrument, revolutionary as they then were, have a very modest appearance beside the schemes now contemplated.

In the matter of mounting the telescope, much additional study will be required before even a preliminary design can be adopted. It is hoped that "an equatorial design of the fork type, of sufficient rigidity to carry a 40 -foot interferometer and meet other severe requirements, will soon be worked out."

In selecting a site for the instrument, precise measures of the 'seeing' rather than estimates have been aimed at. Dr. Anderson has devised "a simple means of measuring the atmospheric oscillations of star images under a power of 600 with a 4-or 5-inch telescope, and Mr. Ellerman has tested it satisfactorily on Mount Wilson, in comparison with the estimates of experienced observers with the 60-inch and 100-inch telescopes. Preliminary observations with this method by Messrs. Ellerman and Humason have been made at Palomar Mountain and 'Horse Flats' (north of Mount Wilson), and some tests made by Dr. Abbot and Mr. Moore at Table Mountain show that this site, like the others, deserves careful examination. Dr. Hubble, with the kind co-operation of the authorities of the Grand Canyon National Park, is engaged in the investigation of conditions near the Grand Canyon and at other points on the high plateau area of Central and Northern Arizona."

The thoroughness which is evident in this part of the plan is characteristic of the whole. Not only the installation of the great telescope itself, but also the arrangements for all the auxiliary instruments and apparatus used to receive, record, and interpret the celestial images, are being subjected to a searching inquiry by an army of the greatest experts in the United States. If determination, skill, and energy can bring the plan to a triumphant issue, it is assured of success. We trust that the practical difficulties of so enormous an undertaking will not prove insurmountable.

\title{
The Transport of Carbohydrates in the Plant.
}

$\mathrm{V}^{\mathrm{m}}$ ERY little is certain as to the movements of carbohydrates in the plant. It is generally agreed that the green plant can build them up for its own needs in leaves exposed to the light, and that these supplies are then utilised in growth throughout the plant, so that considerable movements of sugars must take place from the leaves to the roots and fruits and various storage organs. There is no agreement, however, as to the tissue through which this movement takes place. Only two tissues, regularly present in this plant axis, are so extended in the longitudinal direction as to be very likely to convey such substances for long distances through the axis ; these are the wood or xylem, and the phloem or bast. Usually, the sievetubes of the phloem have been regarded as the channels of sugar transport, as micro-chemical observations, such as those of Prof. Mangham, seemed to show considerable quantities of sugar in these tissues. The phloem in many trees is confined to a narrow layer near the periphery, so that it is possible to cut this channel completely by removing a narrow strip of tissue from the outside of the stem, and there is evidence that such ringing experiments always interfere with carbohydrate transport. Prof. H. H. Dixon pointed out, however (NATURE, vol. 110,547-55l: 1922), that the xylem sap usually contains appreciable quantities of sugar, and that in the ringing experiment it is very difficult to remove the phloem without doing some damage to the wood. As a result, the wood may be partially blocked, so that the interruption of the carbohydrate movement, attributed to the ringing of the phloem, may be really due to the partial choking of the xylem channels.

In much of the experimental work done to elucidate this problem, the transfer of carbohydrates through the region of the axis experimented upon is gauged by the amount of growth afterwards made as the result of supplies assumed to come from sources on the other side of the ring. Thus Prof. Otis F. Curtis has published a series of observations upon ringed shoots which were defoliated above the ring, and as a result made little growth, presumably through the failure of supplies to cross the ring. In such experiments the plants have obviously to be left for some time following the original ringing operation, and though Prof. Curtis has on many occasions followed up his observation of growth by quantitative analyses of his plants for carbohydrates, nitrogen, etc., it is difficult to know how much the redistribution observed has been determined by metabolic activities connected with growth, and how much it has been directly the

$$
\text { No. 3091, Vor. 123] }
$$


result of the interruption of translocation in the phloem. None the less, the work of Prof. Curtis has established a very strong presumption that the phloem is at least very active in the transfer of carbohydrates and probably many other substances through the axis of the plant. In two recent papers by Messrs. Mason and Maskell in the Annals of Botany (vol, 42, January 1928 and July 1928), a great deal of new evidence is supplied which points in the same direction. The Empire Cotton Growing Corporation has recently issued a reprint of these papers, ${ }^{1}$ which form an outstanding contribution, based upon an intensive study of the cotton plant, to the solution of the general problem of the transport of carbohydrates in the higher plant. The papers occupy together more than 120 pages, and they describe much suggestive experimental work, with critical discussion of procedure and results, for which reference must be made to the original papers.

The experimental method adopted by Messrs. Mason and Maskell has been to follow, by analytical methods that permitted of certain standard determinations on numerous samples in a limited time, the changes in carbohydrate content in isolated samples of leaf, wood, and bark (the latter tissue including the phloem) within periods of time usually not greater than two or three hours. Sucrose, reducing sugars, and reserve carbohydrates were estimated separately, and the results expressed on the basis of the residual dry weight (total dry weight less carbohydrates) as a quantity that is less liable to fluctuation than either fresh weight or dry weight. Unfortunately, at each sampling an experimental plant is sacrificed, so that large numbers of plants of one strain of Sea Island cotton were grown under as uniform cultural conditions as possible, several samples taken and analysed. separately on each occasion, and statistical methods applied to the whole series of results obtained in any one experiment, so that significant correlations and differences might be determined. In these experiments, therefore, any movements of carbohydrates that may be indicated will be the direct result of a fairly rapid longitudinal movement of these substances through the tissues, and not the indirect result of growth activities, which are not likely to produce very appreciable changes in such short time periods.

The immediate result of the new experimental method was to establish a significant correlation between the diurnal variation in the concentration of sugars in the leaf with similar variations in the bark, but not usually in the wood. At a distance some $50 \mathrm{~cm}$. or more below the leaf, the variation of concentrations in the bark seems to follow the same curve, but is two or three hours later in reaching similar points on the curve. Reserve carbohydrates, which fluctuate greatly in the leaf, show little or no change in wood or bark, and are not considered further in the present brief discussion. In experiments in March, fruit bolls were included,

1 "Memoirs of the Cotton Research Station, Trinidad, Series B, Physiology, No. 1. Studies on the Transport of Carbohydrates in the Cotton Plant." By T. G. Mason and E. J. Maskell. Empire Cotton Growing Corporation, 2 Wood Street, Millbank, London, S.W.1. 1928. and samples of wood and bark lying between leaf and boll. The result was to show significant correlations with similar time lag in the sugar content of leaf and bark and the dry weight increase in the developing fruit.

In September and later months, the results of ringing experiments were examined by the same methods at six-hourly intervals after the ring was made, with the result that above such a ring, made below the leafy region of the plant, an accumulation of sugars was soon observed in both wood and bark, whilst in the $6 \frac{1}{2}$ inches of wood and bark just below the ring there is a marked fall in total carbohydrates. In this case correlated changes were noted in both wood and bark, and these and other experiments suggest to the investigators that an accumulation of sugars in the bark at any region is followed by a slow radial transfer of sugar into the wood in this region. Other ringing experiments, however, in which flaps of bark were lifted off the wood and separated from it during experiment by paraffined paper or vaseline, showed that, provided these strips of isolated bark remained connected to the foliar region above by continuous channels in the bark, accumulation of sugar still took place in them, though they ceased in the wood in the same region.

These experiments, on the whole, seem to provide very definite evidence that the major movement of carbohydrates from the synthetic centres of the leaves takes place through the phloem, though the possibility of carbohydrate movement under certain conditions in the xylem is, of course, not excluded. Experiments in the second paper, in which different regions of the phloem are analysed separately, suggest that the inner region, which consists more predominantly of sieve tubes, and possibly to a large extent of developing ones, is the region in which most of the longitudinal movement takes place, because the concentration of sucrose is much higher in the inner region, so that the concentration gradient of sucrose outwards in a radial direction is $300-500$ times as steep as in a longitudinal direction.

Whilst Mason and Maskell have thus supplied striking experimental evidence in favour of movement of sugars through the phloem, they do not fail to point out the difficulties in the way of understanding this phenomenon. Changes of sugar concentration in the leaf sap are followed by changes in the phloem of the axis, as if the concentration gradient determined the movement of sugar, as it would do in the case of movement by diffusion. But from the rapidity with which these concentration changes are registered at distances of more than fifty centimetres, they calculate that the longitudinal movement of the sugar in the sieve tube is at least 20,000 times too fast to be due to diffusion of sugar through an aqueous medium. Furthermore, there is another stumblingblock in the way of regarding the concentration gradient as the driving force determining movement. In the leaf the variation is principally in reducing sugars, and this is followed by changes in the concentration of sucrose in the phloem. They conclude, 
therefore, that sugar moves in the sieve tukes by a process analogous to diffusion, but that the mechanism by which such high absolute rates of movement are maintained is unknown.

In this connexion the possibilities of streaming movements in the segments of the sieve tube might be worthy of further examination. It is a well-known fact that in many elongated living cells the protoplasm of the cell rotates within its wall at speeds which would permit of movement along the cell at rates of several centimetres an hour. There is still the need of transfer from one rotating protoplast to the next on the opposite side of a cellulose wall, but the distance thus traversed by diffusion will not be more than $\frac{1}{10}$ the total distance travelled in the sieve tube. This method of transfer would then result in movement, which would obey the concentration gradient, and yet be very nuch more rapid than diffusion in water. Mason and Maskell apparently reject it because protoplasmic rotation is rarely seen in the adult sieve tube although it has been reported by Lecomte. On the other hand, in sections of young developing phloem, as in tangential longitudinal sections through the inner bark of trees, which are mounted in water, most lively streaming movements are usually visible. Strasburger has also shown how readily similar movement can be seen in long cells in the phloem of herbaceous plants which were very possibly developing sieve tubes.
Whilst the adult sieve tube, therefore, may act as a reservoir, which is gradually depleted by local utilisation of its contents, the streaming segment of the developing tube may be responsible for the rapid longitudinal transfer of the carbohydrates. Mason and Maskell eliminated, so far as possible, the complications introduced by growth activities by cutting down the duration of their successive experiments so far as possible. But the inner segment of the phloem in which the very high concentration of sucrose was observed would contain all the young sieve tubes developing from the cambium.

This consideration might throw some light upon a gradient of reducing sugars in the leaf being followed by an.equivalent gradient of sucrose in the phloem of the axis. Any enzyme synthesis of sucrose from glucose and fructose in vitro has so far proved impossible, and in the light of modern knowledge of the difficulties of sucrose synthesis (NATURE, Oct. 13,1928, p. 578), this is quite explicable. In the sieve tube it is difficult to see how the direct conversion of reducing sugar to sucrose is to be brought about, but if the reducing sugars are employed in the construction of living protoplasm, which is then utilised in the construction of a new series of sieve tubes from the cambium, in the differentiating sieve tube sucrose may be found instead of the hexoses which originally entered into the composition of the protoplasm. J. H. Priestrey.

\section{Obituary.}

Dr. J. W. L. GLaisher, F.R.S.

$\mathrm{D}^{\mathrm{B}}$ R. J. W. L. GLAISHER died on Dec. 7, 1928, at the age of eighty years. At the time of his death he was the senior among the actual fellows of Trinity College, Cambridge; was the senior member of the London Mathematical Society; and was almost the senior in standing among the fellows of the Royal Society and the fellows of the Royal Astronomical Society. In his prime he ranked as one of the recognised English pure mathematicians of his generation, pursuing mainly older subjects by methods that were direct and simple. Throughout his life he was devoted to astronomy, chiefly in its mathematical developments. In the later part of his life he attained high rank as an authority on pottery, of which he had made a select collection, famous and invaluable.

Glaisher was the elder son of James Glaisher, F.R.S., himself an astronomer, a mathematician specially devoted to the calculation of numerical tables, and a pioneer in meteorology, sometimes at the risk of his life. For the father was an aeronaut of note; with Coxwell in 1862 he made the dangerous balloon ascent which reached the greatest height (about seven miles) ever recorded by survivors. This aeronautical achievement inspired a popular music-hall song of the day; and "Up in a balloon, boys," was sung by the undergraduate gallery in the Cambridge Senate-House as the aeronaut's distinguished son was being admitted to his first degree.

$$
\text { No. 3091, VoL. 123] }
$$

James Whitbread Lee Glaisher was born at Lewisham, in Kent, on Nov. 5, 1848. He was sent to St. Paul's School in London, which in 1867 he left as the Campden Exhibitioner. In that year he went into residence at Trinity College, Cam. bridge; and that was his home for the rest of his life. He was duly elected a scholar in 1868. He graduated as Second Wrangler in 1871, the Senior Wrangler being John Hopkinson, also a Trinity scholar, later the distinguished engineer. He was elected a fellow of his College in that same year; the election was doubly notable, for it was the first held after the parliamentary removal of dissenters' disability of fellowship tenure, and all the three successful candidates (the other two being Hopkinson and the present Dean of Ely) were elected at their earliest date of candidature.

Glaisher was appointed assistant tutor of his College on Oct. 12, 1871, an office that qualified for the lay retention of his fellowship, though celibate restrictions existed for another eleven years. He was tutor from 1883 until 1893, for the then customary normal period. He remained a lecturer on the mathematical staff until 1910, having been continued beyond the normal maximum period by the College Council.

Glaisher never held any permanent appointment outside Cambridge. It was currently believed that, on Airy's retirement in 1881 , he refused the office of Astronomer Royal which had been offered to him; the duty would, of course, have exacted 